\title{
Pharmacokinetic Optimization of Everolimus Dosing in Oncology: A Randomized Crossover Trial
}

\author{
Remy B. Verheijen ${ }^{1}$ - Florence Atrafi ${ }^{2} \cdot$ Jan H. M. Schellens ${ }^{3,4}$. \\ Jos H. Beijnen ${ }^{1,4} \cdot$ Alwin D. R. Huitema $^{1,5}$ - Ron H. J. Mathijssen ${ }^{2}$. \\ Neeltje Steeghs ${ }^{3}$
}

Published online: 31 July 2017

(c) The Author(s) 2017. This article is an open access publication

\begin{abstract}
Background The mammalian target of rapamycin (mTOR) inhibitor everolimus is used in the treatment of breast cancer, neuroendocrine tumors, and renal cancer. The approved $10 \mathrm{mg}$ once-daily dose is associated with considerable adverse effects and it has been suggested that these are associated with the maximum concentration $\left(C_{\max }\right)$ of everolimus. Twice-daily dosing might be an alternative strategy with improved tolerability; however, a direct pharmacokinetic comparison of $10 \mathrm{mg}$ once-daily with $5 \mathrm{mg}$ twice-daily dosing is lacking.
\end{abstract}

Remy B. Verheijen

r.verheijen@nki.nl

1 Department of Pharmacy and Pharmacology, The Netherlands Cancer Institute-Antoni van Leeuwenhoek, Louwesweg 6, 1066 EC Amsterdam, The Netherlands

2 Department of Medical Oncology, Erasmus MC Cancer Institute, Rotterdam, The Netherlands

3 Department of Medical Oncology and Clinical Pharmacology, The Netherlands Cancer Institute-Antoni van Leeuwenhoek, Amsterdam, The Netherlands

4 Department of Pharmaceutical Sciences, Utrecht University, Utrecht, The Netherlands

5 Department of Clinical Pharmacy, University Medical Center Utrecht, Utrecht, The Netherlands
Methods We performed a prospective, randomized, pharmacokinetic, crossover trial comparing everolimus $10 \mathrm{mg}$ once daily with $5 \mathrm{mg}$ twice daily. Patients received the first dose schedule for 2 weeks and then switched to the alternative regimen for 2 weeks. Pharmacokinetic sampling was performed on days 14 and 28.

Results Eleven patients were included in the study, of whom 10 were evaluable for pharmacokinetic analysis. On the $10 \mathrm{mg}$ once-daily schedule, $C_{\max }$, minimum concentration $\left(C_{\mathrm{min}}\right)$, and area under the concentration-time curve from time zero to $24 \mathrm{~h}\left(\mathrm{AUC}_{24}\right)$ were $61.5 \mathrm{ng} / \mathrm{mL}$ [mean percentage coefficient of variation (CV\%) 29.6], $9.6 \mathrm{ng} / \mathrm{mL}$ (CV\% 35.0), and $435 \mathrm{ng} \mathrm{h} / \mathrm{mL}$ (CV\% 28.1), respectively. Switching to the $5 \mathrm{mg}$ twice-daily schedule resulted in a reduction of $C_{\max }$ to $40.3 \mathrm{ng} / \mathrm{mL}(\mathrm{CV} \% 46.6)(p=0.013)$, while maintaining $\mathrm{AUC}_{24}$ at $436 \mathrm{ng} \mathrm{h} / \mathrm{mL}(\mathrm{CV} \%$ 34.8) $(p=0.952) . C_{\min }$ increased to $13.7 \mathrm{ng} / \mathrm{mL}(\mathrm{CV} \% 53.9)$ $(p=0.018)$. The overall reduction in $C_{\max }$ was $21.2 \mathrm{ng} /$ $\mathrm{mL}$, or $32.7 \%$. The $C_{\max } / C_{\min }$ ratio was reduced from 6.44 (CV\% 36.2) to 3.18 (CV\% 35.5) $(p<0.001)$.

Conclusions We demonstrated that switching from a oncedaily to a twice-daily everolimus dose schedule reduces $C_{\max }$ without negatively impacting $C_{\min }$ or $\mathrm{AUC}_{24}$. These results merit further investigation of the twice-daily schedule in an effort to reduce everolimus toxicity while maintaining treatment efficacy.

Registration This trial was registered in the EurdaCT database (2014-004833-25) and the Netherlands Trial Registry (NTR4908). 


\section{Key Points}

The approved $10 \mathrm{mg}$ once-daily everolimus dose is associated with considerable adverse effects, which have been suggested to be associated with maximum concentration $\left(C_{\max }\right)$.

Twice-daily dosing could lower $C_{\max }$ and thereby lead to improved tolerability.

As a direct pharmacokinetic comparison of $10 \mathrm{mg}$ once daily with a $5 \mathrm{mg}$ twice-daily regimen was lacking, we performed a prospective, randomized, pharmacokinetic, crossover trial in cancer patients to compare the pharmacokinetics of everolimus $10 \mathrm{mg}$ once daily with $5 \mathrm{mg}$ twice daily.

Switching to twice-daily everolimus dosing reduced $C_{\max }$ without negatively impacting minimum concentration or area under the concentration-time curve from time zero to $24 \mathrm{~h}$. These results merit further investigation of the twice-daily schedule in an effort to reduce everolimus toxicity while maintaining treatment efficacy.

\section{Background}

Everolimus is a mammalian target of rapamycin (mTOR) inhibitor approved for the treatment of renal cell carcinoma [1], neuroendocrine tumors [2], and hormone receptor (HR)-positive, human epidermal growth factor receptor 2 (HER2)-negative breast cancer [3]. Inhibition of mTOR has been shown to enhance the effectiveness of hormonalbased therapies for breast cancer patients who have become resistant to endocrine therapy [4].

The BOLERO-2 trial showed that the addition of everolimus to exemestane increased progression-free survival in patients with HR-positive, HER2-negative advanced breast cancer compared with placebo [3]. This improvement from 4.1 to 11.1 months resulted in a hazard ratio of 0.38 (95\% confidence interval $0.31-0.48, p<0.0001)$ in the final analysis [5]. Nonetheless, the everolimus $10 \mathrm{mg}$ once-daily dose in combination with exemestane $25 \mathrm{mg}$ once daily resulted in significant adverse events (AEs) (any grade): $56 \%$ of patients developed stomatitis, $36 \%$ developed rash, 33\% developed fatigue, and 30\% developed diarrhea. These events were severe (grade 3 ) in $8,1,3$, and $2 \%$ of patients, respectively, and a considerable $19 \%$ of patients discontinued treatment due to toxicity. Moreover, a meta-analysis of over 900 patients included in various everolimus phase II trials by Ravaud et al. estimated the overall incidence of stomatitis at $57 \%$ (any grade) and the incidence of severe (grade 3-4) stomatitis at 6\% [6]. Adverse effects, particularly stomatitis, have been shown to be related to pharmacokinetic exposure to everolimus $[6,7]$. Specifically, these AEs may be associated with high maximum plasma concentrations $\left(C_{\max }\right)$ [8]; thus, reducing $C_{\max }$ while maintaining efficacious trough concentrations $\left(C_{\mathrm{min}}\right)$ could be an effective method of optimizing the treatment of everolimus by reducing toxicity yet retaining efficacy.

Generally, the various pharmacokinetic parameters $C_{\min }, C_{\max }$, and area under the whole blood concentrationtime curve (AUC) will be strongly interrelated (i.e. a higher dose will increase all three, and, conversely, a dose reduction will reduce all three). However, in contrast to lowering the once-daily dose (the current strategy to reduce toxicity in clinical practice), switching to a twicedaily schedule could specifically reduce $C_{\max }$ without negatively impacting $C_{\min }$ or AUC, and thereby theoretically reduce toxicity while not reducing efficacy. A strategy to reduce the $C_{\max } / C_{\min }$ ratio could be the use of an extended- or sustained-release formulation [8], or splitting the intake moments from once daily to twice daily.

We hypothesized that given the pharmacological properties of everolimus, the latter approach could reduce the $C_{\max }$ while maintaining the $C_{\min }$ and total exposure, measured as AUC at similar levels. This could lead to reducing the $C_{\max } / C_{\min }$ ratio without the need to develop a new sustained-release formulation, thereby preventing a costly patent extension. To test this hypothesis, we performed a randomized, pharmacokinetic, crossover trial of everolimus $10 \mathrm{mg}$ once daily versus $5 \mathrm{mg}$ twice daily in cancer patients.

\section{Methods}

\subsection{Study Design}

We performed a prospective, multicenter, randomized, crossover trial. An overview of the trial design is given in Fig. 1. Patients were randomized to start with either a 10 $\mathrm{mg}$ once-daily or $5 \mathrm{mg}$ twice-daily dose, and each patient was treated for at least 2 weeks with each dose schedule. Patients were instructed to take everolimus daily, at the same time each day, with a low-fat meal. Patients requiring a dose reduction due to toxicity were considered nonevaluable for the pharmacokinetic endpoint and were replaced. 


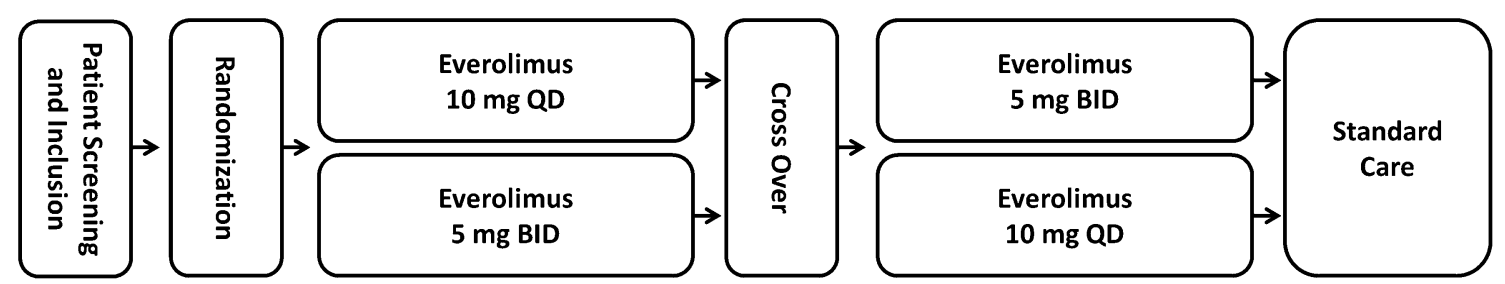

Fig. 1 Trial design. Patients were randomized to start with a 2-week period of an everolimus $5 \mathrm{mg}$ twice-daily dose or an everolimus $10 \mathrm{mg}$ once-daily dose. Pharmacokinetic sampling was performed

\subsection{Patient Population}

Patients with histopathologically confirmed advanced cancer for whom everolimus was considered standard of care were eligible for inclusion. Further inclusion criteria were age $>18$ years, and minimal acceptable safety laboratory values, defined as absolute neutrophil count $\geq 1.5 \times 10^{9} / \mathrm{L}$, platelet count of $>100 \times 10^{9} / \mathrm{L}$, bilirubin $<1.5$ times the upper limit of normal (ULN), aspartate aminotransferase (AST) and alanine aminotransferase (ALT) $<2.5$ times the ULN, creatinine $<1.5$ times the ULN, or creatinine clearance $>50 \mathrm{~mL} / \mathrm{min}$.

Exclusion criteria were the use of any concomitant medication (including over-the-counter and herbal medication) that would induce or inhibit the function of cytochrome P450 (CYP) 3A4.

\subsection{Pharmacokinetics}

At the end of each 2-week period (days 14 and 28), blood samples were collected for pharmacokinetic analysis. In the $10 \mathrm{mg}$ once-daily schedule, samples $(3 \mathrm{~mL})$ were collected at $0,0.5,1,2,3,4,5,6,12$, and $24 \mathrm{~h}$ after drug administration, while in the $5 \mathrm{mg}$ twice-daily schedule sampling times were $0,0.5,1,2,3,4,5,6,12,12.5,13,14,15,16$, and $24 \mathrm{~h}$ after ingestion of the last dose. On the days of pharmacokinetic sampling, everolimus was taken concomitantly with a low-fat meal. Whole-blood everolimus concentrations were measured using a validated liquid chromatography tandem mass spectrometry (LC-MS/MS) method.

\subsection{Bioanalysis}

A $200 \mu \mathrm{L}$ aliquot of whole blood was transferred to an Eppendorf tube, and a $40 \mu \mathrm{L}$ volume of $75 \mathrm{ng} / \mathrm{mL}$ internal standard $\left({ }^{13} \mathrm{C},{ }^{2} \mathrm{H}_{3}\right.$-everolimus) in methanol and $1.0 \mathrm{~mL}$ of tert-butyl methyl ether was added. Samples were vortexed and shaken for $5 \mathrm{~min}$ at $1500 \mathrm{rpm}$, before being centrifuged at 23,100 $\mathrm{g}$ for $5 \mathrm{~min}$. Liquid-liquid extraction was then followed by snap freezing the samples and transferring the organic phase to a new Eppendorf tube. The after each 2-week period (days 14 and 28). qd once daily, bid twice daily

organic phase was then evaporated under a gentle stream of nitrogen. The residue was reconstituted in water with $20 \mathrm{mM}$ ammonium formate and methanol $(1: 1, \mathrm{v} / \mathrm{v})$, of which $5 \mu \mathrm{L}$ was injected in the LC-MS/MS system [HPLC 1100 series (Agilent) and API3000 mass spectrometer (Sciex)]. Chromatographic separation was performed on a Sunfire C18 column (Waters) using $20 \mathrm{mM}$ ammonium formate in water and a gradient of 50-100\% methanol. The bioanalytical assay was validated in accordance with US FDA guidelines for bioanalytical method validation. The analytical range was $1-100 \mathrm{ng} / \mathrm{mL}$. Inter-run and intra-run precision were $\leq 8.5 \%$, and overall and intra-run bias was within $\pm 11 \%$. Carryover was $\leq 5.3 \%$ of the lower limit of quantitation ( $1 \mathrm{ng} / \mathrm{mL}$ ), and the matrix effect (quantified as the $\mathrm{CV}$ of the internal standard normalized matrix factor) was $\leq 1.7 \%$.

\subsection{Study Endpoint}

The primary endpoint of this trial was to describe and compare the pharmacokinetics of everolimus in whole blood after a $10 \mathrm{mg}$ once-daily dose and a $5 \mathrm{mg}$ twicedaily dose. Parameters of particular interest were $C_{\max }$, $C_{\text {min }}$, and AUC from time zero to $24 \mathrm{~h}\left(\mathrm{AUC}_{24}\right)$. The safety of both dose schedules was included as an exploratory endpoint.

\subsection{Safety Assessments}

Recording of AEs, physical examination, and hematology and blood chemistry assessments were performed every 2 weeks. The incidence, severity, and start and end dates of all serious AEs (SAEs) and non-serious AEs were recorded. AEs were graded according to the Common Terminology Criteria for Adverse Events (CTCAE) version 4.02.

\subsection{Statistics}

All statistical analyses were performed in $\mathrm{R}$ version 3.3.2 (R Project, Vienna, Austria) [9]. Pharmacokinetic parameters were calculated using non-compartmental analysis. $C_{\text {max }}$ was defined as the higher of the two observed peaks 
for the twice-daily schedule, while $C_{\min }$ was defined as the average of $t=0$ and $24 \mathrm{~h}$, and $t=0,12$, and $24 \mathrm{~h}$, for the once-daily and twice-daily schedules, respectively. Twosided paired t-tests were used to assess the difference between the calculated pharmacokinetic parameters of the two dose schedules.

Given the descriptive nature of the pharmacokinetic endpoint in this pilot study, it was unfeasible to perform a meaningful formal power analysis; hence, no calculation for the exact number of patients is given. The proposed number of patients is therefore based on comparable pharmacokinetic pilot studies and a conservative estimate of the number of eligible patients. However, in an exploratory analysis, it was calculated that with a sample size of five evaluable subjects in each sequence group (a total sample size of ten subjects), a $2 \times 2$ crossover design will have $80 \%$ power to detect a difference in mean $C_{\max }$ of $17.5 \mathrm{ng} / \mathrm{mL}$ (the difference between a mean, $\mu_{1}$, of $61 \mathrm{ng} /$ $\mathrm{mL}$ for one treatment and a mean, $\mu_{2}$, of $43.5 \mathrm{ng} / \mathrm{mL}$ for the other treatment), assuming that the $\sqrt{ }$ mean standard error is 12.021 (the standard deviation of differences, $\sigma_{\mathrm{d}}$, is 17 [10] using a two-group $t$ test with a 0.050 two-sided significance level. The sample size calculation was performed using the nQuery Advisor software package version 7.0 (Statistical Solutions Ltd).

\subsection{Study Conduct and Registry}

This trial was conducted in accordance with the World Medical Organization Declaration of Helsinki, compliant with Good Clinical Practice, and approved by the Medical Ethics Committee of each participating medical center (The Netherlands Cancer Institute and Erasmus MC Cancer Institute). All patients provided written informed consent prior to enrollment in the study. This trial was registered in the EudraCT database (2014-004833-25) and the Netherlands Trial Registry (NTR4908).

\section{Results}

\subsection{Patient Population}

In total, 11 patients provided written informed consent, of whom four had breast cancer, four had renal cell cancer, and three had neuroendocrine tumors. One patient with breast cancer withdrew consent after pharmacokinetic sampling on day 14 , and the remaining 10 patients were evaluable in both dose schedules. No patients required a dose reduction. An overview of the characteristics of the evaluable patients is provided in Table 1 . The four breast cancer patients used everolimus in combination with exemestane $25 \mathrm{mg}$, in accordance with the summary of
Table 1 Baseline characteristics of evaluable patients $(n=10)$

\begin{tabular}{lc}
\hline Characteristic & $n(\%)$ or mean (range) \\
\hline Sex & $5(50 \%)$ \\
Male & $5(50 \%)$ \\
Female & $56(43-78)$ \\
Age (years) & $171(161-192)$ \\
Height (cm) & $76(52-92)$ \\
Weight (kg) & \\
WHO performance status & $4(40 \%)$ \\
0 & $6(60 \%)$ \\
1 & \\
Tumor type & $3(30 \%)$ \\
Breast & $4(40 \%)$ \\
Renal & $3(30 \%)$ \\
Neuroendocrine & \\
Previous systemic therapy & $6(60 \%)$ \\
Chemotherapy & $5(50 \%)$ \\
Targeted therapy & $4(40 \%)$ \\
Endocrine therapy &
\end{tabular}

product characteristics. Of all the enrolled patients, 30\% had already received everolimus prior to inclusion in the trial.

\subsection{Pharmacokinetics}

Absolute and relative change in $C_{\max }$ for each individual patient are displayed in Table 2 . The mean reduction in $C_{\max }$ achieved by switching from a once-daily to a twicedaily dose was $21.2 \mathrm{ng} / \mathrm{mL}$, or $32.7 \%$ ( $p=0.013$ ). All but one patient showed a reduction in $C_{\max }$. For this patient, only one of the two peak values on the twice-daily schedule (79.4 and $40.2 \mathrm{ng} / \mathrm{mL}$ ) was above the $C_{\max }$ of the oncedaily schedule $(56.9 \mathrm{ng} / \mathrm{mL})$; however, the highest of both peaks was used for calculation of the change in $C_{\max }$.

An overview of the pharmacokinetic parameters for each of the dose schedules is provided in Table 3. Changes in $\mathrm{AUC}_{24}$ and time to $C_{\max }\left(T_{\max }\right)$ were not statistically significant ( $p=0.70$ and 0.95 , respectively). Box plots comparing selected pharmacokinetic parameters of the once-daily and twice-daily schedules are shown in Fig. 3.

Interpatient variability [percentage coefficient of variation $(\mathrm{CV} \%)$ ] for $\mathrm{AUC}_{24}, C_{\max }$, and $C_{\min }$ were 28.1, 29.6, and $36.2 \%$, respectively, for the $10 \mathrm{mg}$ once-daily dose level, and $35.5,46.6$, and $53.9 \%$, respectively, for the $5 \mathrm{mg}$ twice-daily dose level. Intrapatient variability (quantified as an intrapatient $\mathrm{CV} \%$ on $t=0$ and $t=24$ for each schedule) was relatively small, with a mean intrapatient $\mathrm{CV}$ of $11.1 \%$ on the twice-daily schedule and $6.8 \%$ on the once-daily schedule.

The hematocrit values of patients (which could impact the whole-blood pharmacokinetics of everolimus) did not 
Table 2 Absolute and relative change in $C_{\max }$ after switching from $10 \mathrm{mg}$ once daily to $5 \mathrm{mg}$ twice daily for each individual patient (concentration and percentage)

\begin{tabular}{lll}
\hline ID & $C_{\max }$ reduction $(\mathrm{ng} / \mathrm{mL})^{\mathrm{a}}$ & $C_{\max }$ reduction $(\%)$ \\
\hline 1 & 5.5 & 12.1 \\
2 & 14.9 & 48.1 \\
3 & 35.1 & 47.5 \\
4 & 21.1 & 47.4 \\
5 & 3.4 & 5.5 \\
6 & -22.5 & -39.5 \\
7 & 30.1 & 44.1 \\
8 & 48.4 & 67.6 \\
9 & 31.4 & 47.4 \\
10 & 44.5 & 46.6 \\
Mean & $21.2 \mathrm{ng} / \mathrm{mL}$ & $32.7 \%$ \\
\hline
\end{tabular}

$C_{\max }$ maximum concentration

a $C_{\max }$ is defined as the highest of the two observed peaks for the twice-daily schedule

show marked changes between the two pharmacokinetic visits. Median fold change was 1.05, ranging from $0.97-1.17$. Overall mean hematocrit during the trial was $36.6 \%$.

Five patients were randomized to each treatment arm. The randomization sequence did not seem to impact the outcome of the primary endpoint as the absolute and relative mean $C_{\max }$ reductions in the once-daily to twice-daily arm were $19.4 \mathrm{ng} / \mathrm{mL}$ and $26.8 \%$, compared with $23.0 \mathrm{ng} /$ $\mathrm{mL}$ and $38.5 \%$ in the twice-daily to once-daily sequence arm.

\subsection{Adverse Events}

An overview of all treatment-related AEs is provided in Table 4. Only one patient did not experience any treatment-related AEs. The most common event was oral stomatitis (in all cases limited to grade 1). Only one grade 3 event (ALT elevation) and two grade 2 events (neuropathy and increased AST) occurred during the trial period. Due to the low number of events in the trial period, no distinct differences in toxicity between the two dosing arms or exposure-safety relationships could be distinguished.

\section{Discussion}

The hypothesis of this study was that switching patients from a $10 \mathrm{mg}$ once-daily dose to a $5 \mathrm{mg}$ twice-daily dose would lead to a reduction in $C_{\max }$, which is probably responsible for most of the dose-limiting toxicities, while still maintaining AUC and $C_{\min }$, to guarantee similar efficacy. We have shown that splitting everolimus intake results in a large reduction in $C_{\max }$ and a modest, yet statistically significant, increase in $C_{\min }$ (Table 2; Figs. 2, 3). This resulted in an approximately 50\% reduction in the $C_{\max } / C_{\min }$ ratio of 6.44 on the once-daily schedule, to 3.18 on the twice-daily schedule $(p<0.001)$.

No significant difference in total exposure measured as AUC was detected by splitting the dose into a $5 \mathrm{mg}$ twicedaily regimen. This was the intended outcome and was in concordance with the pharmacokinetic data in the phase I study, which showed no dose-dependent change in bioavailability over a dose range of 5-70 mg [10]. Subsequently, these results support the view that a switch from $10 \mathrm{mg}$ once daily to $5 \mathrm{mg}$ twice daily is feasible and could improve specific pharmacokinetic parameters without affecting overall exposure.

Previous studies have shown a large interpatient variability in the pharmacokinetics of everolimus [7, 10-12]. Our trial confirms this high interpatient variability, with CVs ranging from 28.1 to $53.9 \%$ (Table 2). CVs were numerically higher in the twice-daily arm than in the oncedaily arm. This difference is most likely driven by the single outlier patient (see Table 4) who had an increased $C_{\max }$ on the twice-daily schedule. As food is known to
Table 3 Selected pharmacokinetic properties of everolimus in the $10 \mathrm{mg}$ oncedaily and $5 \mathrm{mg}$ twice-daily schedules

\begin{tabular}{lllr}
\hline Pharmacokinetic parameter & $10 \mathrm{mg}$ once daily & $5 \mathrm{mg}$ twice daily & $p$ value \\
\hline$C_{\max }(\mathrm{ng} / \mathrm{mL})^{\mathrm{a}}$ & $61.5(29.6)$ & $40.3(46.6)$ & $\mathbf{0 . 0 1 3}$ \\
$T_{\max }(\mathrm{h})$ & 1.4 & 2.2 & 0.703 \\
$C_{\min }(\mathrm{ng} / \mathrm{mL})^{\mathrm{b}}$ & $9.6(35.0)$ & $13.7(53.9)$ & $\mathbf{0 . 0 1 8}$ \\
$\mathrm{AUC}_{24}(\mathrm{ng} * \mathrm{~h} / \mathrm{mL})$ & $435(28.1)$ & $436(34.8)$ & 0.952 \\
$C_{\text {max }} / C_{\text {min }}$ ratio & $6.44(36.2)$ & $3.18(35.5)$ & $<\mathbf{0 . 0 0 1}$ \\
\hline
\end{tabular}

Bold values indicate statistically significant $p$ values

Data are expressed as mean $(\mathrm{CV} \%)$

$C_{\max }$ maximum concentration, $T_{\max }$ time to $C_{\max }, C_{\min }$ minimum concentration, $A U C_{24}$ area under the concentration-time curve from time zero to $24 \mathrm{~h}$

a $C_{\max }$ is defined as the higher of the two observed peaks for the twice-daily schedule

b $C_{\min }$ is defined as the average of $t=0$ and $24 \mathrm{~h}$, and $t=0,12$, and $24 \mathrm{~h}$, for the once-daily and twicedaily schedules, respectively 
Table 4 Toxicity data per dose schedule, graded according to CTCAE version 4.02 (only treatment-related toxicities are shown)

\begin{tabular}{llllll}
\hline Adverse event & 5 mg twice daily & & & 10 mg once daily & \\
\cline { 2 - 3 } & Any grade $(n)$ & Grade $\geq 3(n)$ & & Any grade $(n)$ & Grade $\geq 3(n)$ \\
\hline Stomatitis & 2 & 0 & 2 & 0 \\
AST increase & 1 & 0 & 0 & 0 \\
ALT increase & 0 & 1 & 0 & 0 \\
Neuropathy & 1 & 0 & 0 & 0 \\
Fatigue & 1 & 0 & 0 & 0 \\
Nausea & 1 & 0 & 0 & 0 \\
Constipation & 0 & 0 & 1 & 0 \\
Dry skin & 2 & 0 & 0 & 0 \\
Dry mouth & 1 & 0 & 0 & 0 \\
Pruritus & 0 & 0 & 1 & 0 \\
\hline
\end{tabular}

CTCAE Common Terminology Criteria for Adverse Events, $A S T$ aspartate aminotransferase, $A L T$ alanine aminotransferase
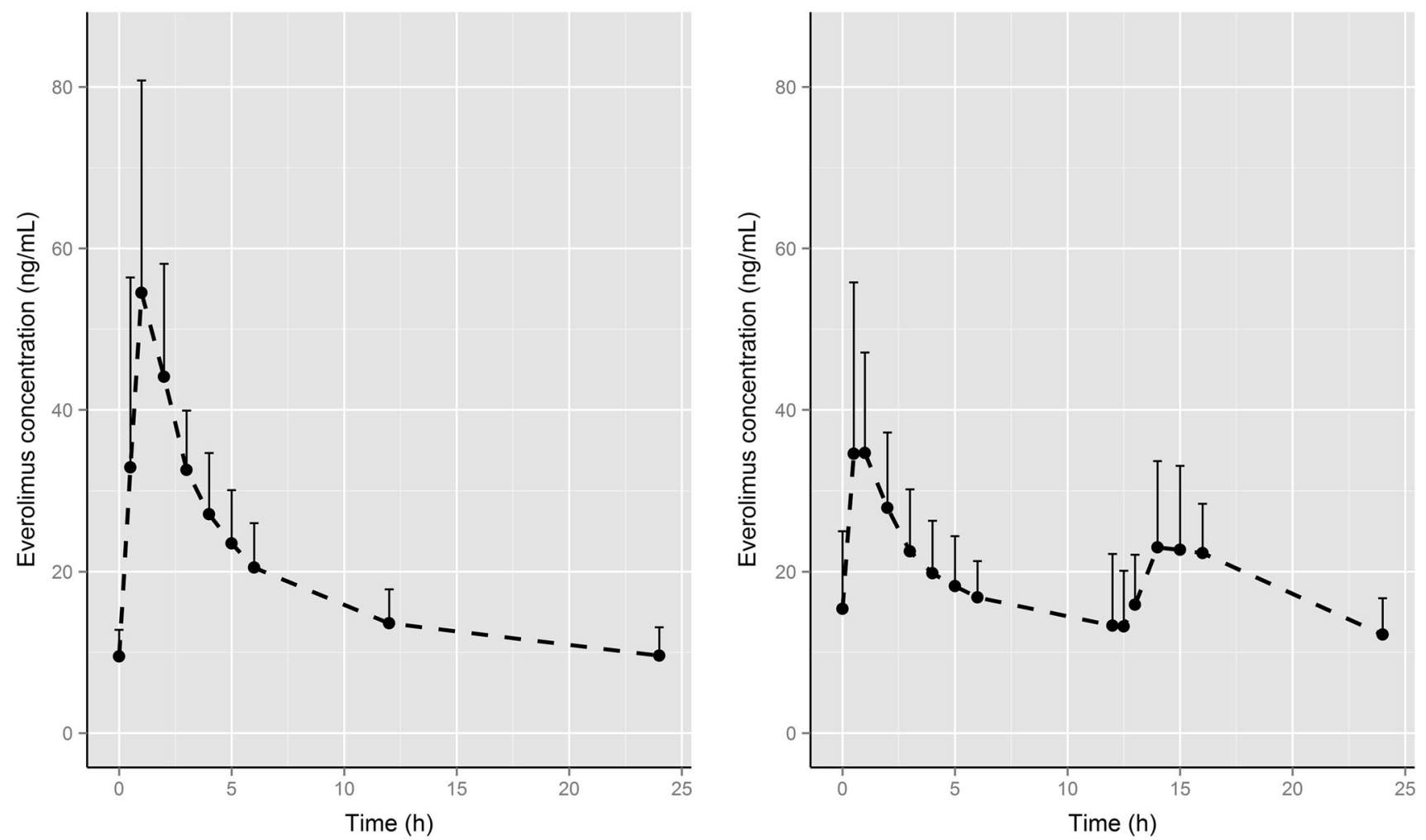

Fig. 2 Whole-blood concentration-time curves (mean + standard deviation) of the $10 \mathrm{mg}$ once-daily (left) and $5 \mathrm{mg}$ twice-daily (right) dose schedules $(n=10)$

affect the pharmacokinetics of everolimus [13], patients were instructed to take everolimus with a low-fat meal during the study period. To further reduce a possible effect of this and other environmental factors on the pharmacokinetic variability of everolimus, we used a crossover design for the current study. Using this design, only intrapatient pharmacokinetic variability could possibly influence the outcome.
As shown in Fig. 2, the $C_{\max }$ achieved on the twicedaily schedule in the evening seemed lower compared with the $C_{\max }$ in the morning. This is most likely due to the larger meal size in the evening as food is known to reduce the absorption of everolimus [13]

In the current study, everolimus was well-tolerated in both dose regimens; however, some patients had already received everolimus prior to enrollment. This limits the 

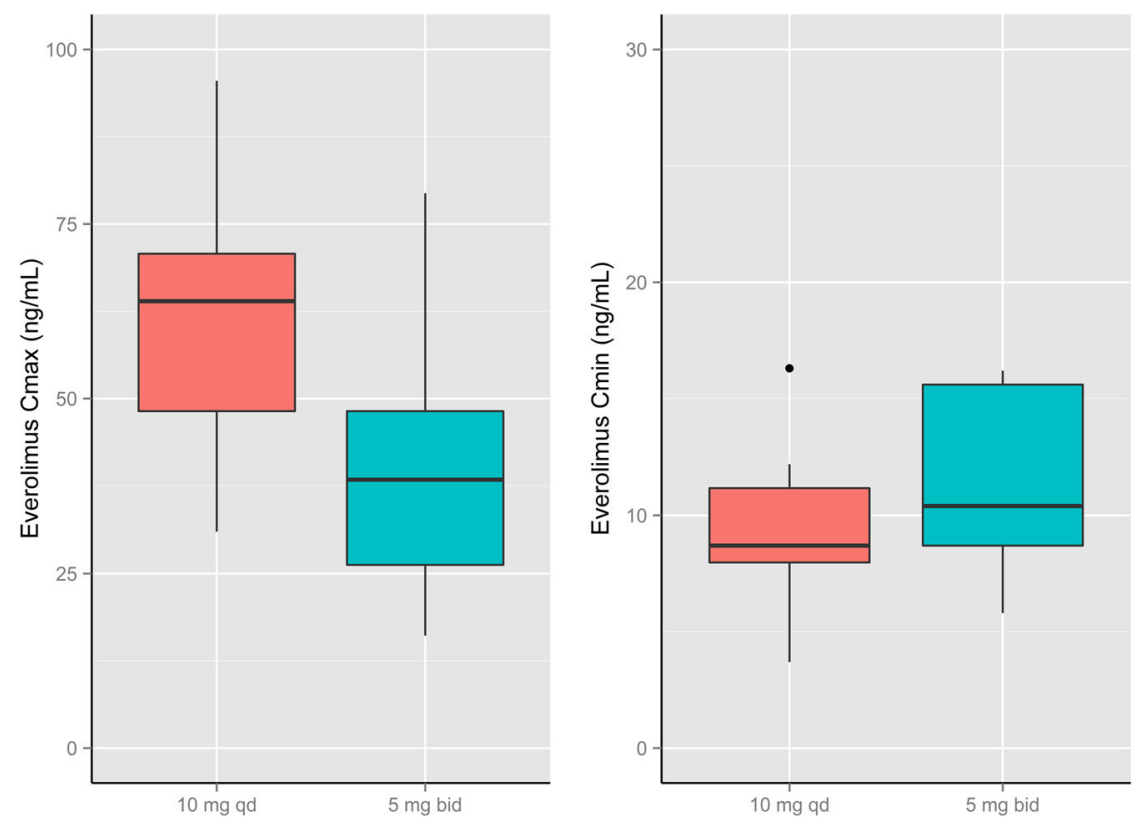

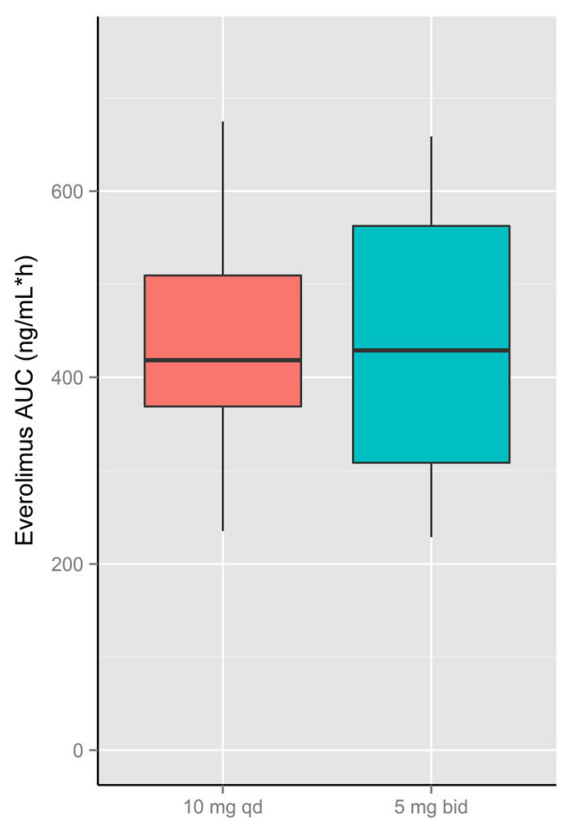

Fig. 3 Box plots of $C_{\max }, C_{\min }$, and $\mathrm{AUC}_{24}$ for both dose schedules. $C_{\min }$ is defined as the average of $t=0$ and $24 \mathrm{~h}$, and $t=0,12$, and $24 \mathrm{~h}$, for the once-daily (orange boxes) and twice-daily schedule (green boxes), respectively. $C_{\max }$ was defined as the higher of the two

comparison of toxicity between the two dose regimens as most everolimus-associated AEs occur soon after the initiation of therapy [14]. Moreover, in the current trial, patients were only treated on each dose schedule for a short duration of merely 2 weeks.

Everolimus $C_{\min }$ has been linked to treatment efficacy in several studies. An analysis of 44 renal cell carcinoma patients proposed a threshold for efficacy of $14.1 \mathrm{ng} / \mathrm{mL}$ [15]. Although not statistically significant, a difference in progression-free survival of 13.3 versus 3.9 months was seen. In pediatric oncology, everolimus is administered based on whole-blood concentrations, and a $C_{\min }$ window of $5-15 \mathrm{ng} / \mathrm{mL}$ is used as the pharmacokinetic target [16]. In pancreatic neuroendocrine tumors, median progressionfree survival was 22.7 months in patients with a $C_{\min }$ of $10-30 \mathrm{ng} / \mathrm{mL}$, compared with only 13.8 months in patients with a $C_{\min }<10 \mathrm{ng} / \mathrm{mL}$ [6]. In a meta-analysis of published phase II trials in various tumor types, a twofold increase in $C_{\min }$ increased the probability of tumor size reduction by $40 \%$, and reduced the risk of progression-free survival events by $10 \%$ [6]. These findings underscore the need to maintain $C_{\min }$ levels. Fortunately, the current strategy of 5 mg twice-daily dosing increased $C_{\min }$ compared with oncedaily dosing, potentially leading to a better progressionfree survival. However, a prospective clinical trial is needed to conclusively demonstrate a reduction in toxicity and improved efficacy for the everolimus twice-daily administration schedule. observed peaks for the twice-daily schedule. $C_{\max }$ maximum concentration, $C_{\min }$ minimum concentration, $A U C_{24}$ area under the concentration-time curve from zero to $24 \mathrm{~h}$, qd once daily, bid twice daily

A drawback of switching to a twice-daily dose schedule might be that it could reduce treatment compliance. However, the effect of once-daily dosing on adherence has been shown to be modest in other therapeutic areas (e.g. only a $2.9 \%$ increase in adherence was seen in a metaanalysis of antiretroviral drugs) [17]. Moreover, it could also be argued that a reduction in toxicity could help maintain treatment adherence and even prevent dose reductions or treatment discontinuation, which are common in everolimus treatment $[3,7]$.

Limitations of the current study include its limited size and duration and the fact that patients could have already received everolimus prior to enrollment. Although the endpoint of a reduced $C_{\max } / C_{\min }$ ratio has been achieved, the relationship between this ratio and toxicity cannot be assessed based on these data.

An alternative strategy to manage toxicity could be to individualize the everolimus dose based on measured $C_{\mathrm{min}}$ levels, also known as therapeutic drug monitoring. Given the high interpatient variability in exposure [10] and the established exposure-efficacy and exposure-toxicity relationships, this would be a rational approach. Moreover, this has already been implemented in everolimus therapy in transplantation medicine [18] and pediatric oncology [16]. Twice-daily dosing could be combined with therapeutic drug monitoring to further manage the pharmacokinetic exposure in everolimus treatment, and, interestingly, in transplantation medicine, everolimus is already routinely 
administered in a twice-daily schedule, albeit at a lower total dose [18].

\section{Conclusion}

This randomized, pharmacokinetic, crossover study in cancer patients indicates that switching from a $10 \mathrm{mg}$ oncedaily to a $5 \mathrm{mg}$ twice-daily dose schedule significantly reduces everolimus $C_{\max }$ without negatively impacting $C_{\text {min }}$ or $\mathrm{AUC}_{24}$. These results merit further investigation of the everolimus twice-daily schedule in oncology in an effort to reduce everolimus toxicity while maintaining treatment efficacy.

Acknowledgements The authors thank all patients for their participation in this study.

\section{Compliance with Ethical Standards}

Ethical approval This trial was conducted in accordance with the World Medical Organization Declaration of Helsinki, compliant with Good Clinical Practice, and approved by the Medical Ethics Committee of each participating medical center (The Netherlands Cancer Institute and Erasmus MC Cancer Institute). All patients provided written informed consent prior to enrollment in the study. This trial was registered in the EurdaCT database (2014-004833-25) and the Netherlands Trial Registry (NTR4908).

Funding This investigator-initiated study was supported by Novartis. The funding source had no involvement in the study design, collection, analysis and interpretation of the data, writing of the report, or in the decision to submit the article for publication.

Conflicts of interest Neeltje Steeghs received funding from Novartis as principal investigator for this investigator-initiated study. Remy B. Verheijen, Florence Atrafi, Jan H.M. Schellens, Jos H. Beijnen, Alwin D.R. Huitema and Ron H.J. Mathijssen declare they have no conflicts of interest to disclose.

Open Access This article is distributed under the terms of the Creative Commons Attribution-NonCommercial 4.0 International License (http://creativecommons.org/licenses/by-nc/4.0/), which permits any noncommercial use, distribution, and reproduction in any medium, provided you give appropriate credit to the original author(s) and the source, provide a link to the Creative Commons license, and indicate if changes were made.

\section{References}

1. Motzer RJ, Escudier B, Oudard S, Hutson TE, Porta C, Bracarda $\mathrm{S}$, et al. Efficacy of everolimus in advanced renal cell carcinoma: a double-blind, randomised, placebo-controlled phase III trial. Lancet. 2008;372:449-56.

2. Yao JC, Shah MH, Ito T, Bohas CL, Wolin EM, Van Cutsem E, et al. Everolimus for advanced pancreatic neuroendocrine tumors. N Engl J Med. 2011;364:514-23.
3. Baselga J, Campone M, Piccart M, Burris HA 3rd, Rugo HS, Sahmoud T, et al. Everolimus in postmenopausal hormone-receptor-positive advanced breast cancer. $\mathrm{N}$ Engl J Med. 2012;366:520-9.

4. Steelman LS, Martelli AM, Cocco L, Libra M, Nicoletti F, Abrams SL, et al. The therapeutic potential of mTOR inhibitors in breast cancer. Br J Clin Pharmacol. 2016;82(5):1189-212.

5. Yardley DA, Noguchi S, Pritchard KI, Burris HA, Baselga J, Gnant M, et al. Everolimus plus exemestane in postmenopausal patients with $\mathrm{HR}+$ breast cancer: BOLERO-2 final progressionfree survival analysis. Adv Ther. 2013;30:870-84.

6. Ravaud A, Urva SR, Grosch K, Cheung WK, Anak O, Sellami DB. Relationship between everolimus exposure and safety and efficacy: meta-analysis of clinical trials in oncology. Eur J Cancer. 2014;50:486-95.

7. de Wit D, Schneider TC, Moes DJAR, Roozen CFM, den Hartigh $\mathrm{J}$, Gelderblom H, et al. Everolimus pharmacokinetics and its exposure-toxicity relationship in patients with thyroid cancer. Cancer Chemother Pharmacol. 2016;78:63-71.

8. Diederich A, Liechti K, Kuehl P, Cheung W. Pharmaceutical compositions comprising 40-O-(2-hydroxy) ethyl-rapamycin. 2013. https://www.google.com/patents/WO2013050419A1?cl= en. Accessed 10 Apr 2017.

9. Verheijen RB, Bins S, Mathijssen RHJ, Lolkema MP, van Doorn L, Schellens JHM, et al. Individualized pazopanib dosing: a prospective feasibility study in cancer patients. Clin Cancer Res. 2016;22:5738-46.

10. O'Donnell A, Faivre S, Burris HA, Rea D, Papadimitrakopoulou $\mathrm{V}$, Shand N, et al. Phase I pharmacokinetic and pharmacodynamic study of the oral mammalian target of rapamycin inhibitor everolimus in patients with advanced solid tumors. J Clin Oncol. 2008;26:1588-95.

11. Kirchner GI, Meier-wiedenbach I, Manns MP. Clinical pharmacokinetics of everolimus. Clin Pharmacokinet. 2004;43:83-95.

12. Moes DJAR, Press RR, Den Hartigh J, Van Der Straaten T, De Fijter JW, Guchelaar HJ. Population pharmacokinetics and pharmacogenetics of everolimus in renal transplant patients. Clin Pharmacokinet. 2012;51:467-80.

13. Kovarik JM, Hartmann S, Figueiredo J, Rordorf C, Golor G, Lison A, et al. Effect of food on everolimus absorption : quantification in healthy subjects and a confirmatory screening in patients with renal transplants. Pharmacotherapy. 2002;22:154-9.

14. Rugo HS, Pritchard KI, Gnant M, Noguchi S, Piccart M, Hortobagyi $\mathrm{G}$, et al. Incidence and time course of everolimus-related adverse events in postmenopausal women with hormone receptor-positive advanced breast cancer: insights from BOLERO-2. Ann Oncol. 2014;25:808-15.

15. Thiery-Vuillemin A, Mouillet G, Nguyen Tan Hon T, Montcuquet P, Maurina T, Almotlak H, et al. Impact of everolimus blood concentration on its anti-cancer activity in patients with metastatic renal cell carcinoma. Cancer Chemother Pharmacol. 2014;73:999-1007.

16. Krueger DA, Care MM, Holland K, Agricola K, Tudor C, Mangeshkar P, et al. Everolimus for subependymal giant-cell astrocytomas in tuberous sclerosis. $\mathrm{N}$ Engl $\mathrm{J}$ Med. 2010;363:1801-11.

17. Parienti JJ, Bangsberg DR, Verdon R, Gardner EM. Better adherence with once daily antiretroviral regimens: a meta analysis. Clin Infect Dis. 2009;48:484-8.

18. Shipkova M, Hesselink DA, Holt DW, Billaud EM, van Gelder T, Kunicki PK, et al. Therapeutic drug monitoring of everolimus: a consensus report. Ther Drug Monit. 2016;38:143-69. 